\title{
A quantitative analysis of adverse radiation effects following Gamma Knife radiosurgery for arteriovenous malformations
}

\author{
Or Cohen-Inbar, MD, PhD, ${ }^{1}$ Cheng-Chia Lee, MD, ${ }^{1-3}$ Zhiyuan Xu, MD, David Schlesinger, PhD, ${ }^{1}$ and \\ Jason P. Sheehan, MD, PhD'1
}

${ }^{1}$ Department of Neurological Surgery, University of Virginia Health System, Charlottesville, Virginia; ${ }^{2}$ Neurological Institute, Taipei Veteran General Hospital; and ${ }^{3}$ National Yang-Ming University, Taipei, Taiwan

\begin{abstract}
OBJECT The authors review outcomes following Gamma Knife radiosurgery (GKRS) of cerebral arteriovenous malformations (AVMs) and their correlation to postradiosurgery adverse radiation effects (AREs).

METHODS From a prospective institutional review board-approved database, the authors identified patients with a minimum of 2 years of follow-up and thin-slice T2-weighted MRI sequences for volumetric analysis. A total of 105 AVM patients were included. The authors analyzed the incidence and quantitative changes in AREs as a function of time after GKRS. Statistical analysis was performed to identify factors related to ARE development and changes in the ARE index.

RESULTS The median clinical follow-up was 53.8 months (range 24-212.4 months), and the median MRI follow-up was 36.8 months (range $24-212.4$ months). $47.6 \%$ of patients had an AVM with a Spetzler-Martin grade $\geq$ III. The median administered margin and maximum doses were 22 and $40 \mathrm{~Gy}$, respectively. The overall obliteration rate was $70.5 \%$. Of patients who showed complete obliteration, 74.4\% developed AREs within 4-6 months after GKRS. Late-onset AREs (i.e., > 12 months) correlated to a failure to obliterate the nidus. $58.1 \%$ of patients who developed appreciable AREs (defined as ARE index > 8) proceeded to have a complete nidus obliteration. Appreciable AREs were found to be influenced by AVM nidus volume $>3 \mathrm{ml}$, lobar location, number of draining veins and feeding arteries, prior embolization, and higher margin dose. On the other hand, a minimum ARE index $>8$ predicted obliteration $(p=0.043)$.
\end{abstract}

CONCLUSIONS ARE development after radiosurgery follows a temporal pattern peaking at 7-12 months after stereotactic radiosurgery. The ARE index serves as an important adjunct tool in patient follow-up and outcome prediction.

http://thejns.org/doi/abs/10.3171/2014.10.JNS142264

KEY WORDS arteriovenous malformation; complication; Gamma Knife; outcome; radiosurgery; T2 changes; stereotactic radiosurgery

I NTRACRANIAL arteriovenous malformations (AVMs) consist of an abnormal nidus of blood vessels that shunt blood directly from an artery to a vein and thereby bypass an intervening capillary bed. ${ }^{1}$ The incidence of AVMs is estimated to be $1.12-1.34$ per 100,000 personyears. ${ }^{2,34}$ These vascular lesions account for $9 \%$ of subarachnoid hemorrhages and $1 \%-2 \%$ of all strokes. ${ }^{25}$

AVMs continue to represent a significant challenge to the cerebrovascular community of health professionals, and opinions differ regarding the optimal management of these lesions. ${ }^{6,8,35,36}$ A number of AVM grading systems have been developed over the years with the ultimate goal of predicting treatment outcomes based on AVM subgroup. ${ }^{18,27,38,41}$ For surgical planning, however, no classification is more widely used than the Spetzler-Martin grading scale because of its simplicity and reliability in predicting microsurgical AVM outcomes. ${ }^{33}$

Radiosurgery has become a standard treatment approach for AVMs and particularly so for those AVMs that have hemorrhaged and are deemed too risky for a resection. Following radiosurgery, $80 \%$ of patients demonstrate obliteration on long-term follow-up. ${ }^{3,5,11,15,19,20,23,28-32,39,42,45}$ During the period following radiosurgery, adverse radiation effects (AREs) accompanied by changes on T2-

ABBREVIATIONS ARE = adverse radiation effect; $A V M=$ arteriovenous malformation; GKRS = Gamma Knife radiosurgery; SRS = stereotactic radiosurgery; VRAS = Virginia Radiosurgery AVM Scale.

SUBMITTED September 30, 2014. ACCEPTED October 31, 2014.

INCLUDE WHEN CITING Published online April 24, 2015; DOI: 10.3171/2014.10.JNS142264.

DISCLOSURE Dr. Schlesinger reports receiving support of non-study-related clinical or research efforts from Elekta Instruments AB. 
weighted or FLAIR sequences are seen in the perinidal region, and such changes may occur in a substantial portion of patients. ${ }^{43}$ The AREs may be accompanied by temporary symptoms in some patients, and, rarely, they may translate into permanent symptoms. In a somewhat ironic fashion, these same T2-weighted or FLAIR findings often predict AVM obliteration for many patients. ${ }^{38}$

In this study, we quantitatively analyze the timing and volumetric changes of these AREs in a series of AVM patients treated with Gamma Knife radiosurgery (GKRS). Moreover, we assess the factors that relate to persistence as compared with transient ARE changes on MRI.

\section{Methods}

From 1987 to 2012, more than 1400 patients with cerebral AVMs were treated at the University of Virginia Health System. The institutional review board approved the collection and use of the patient data. In this study we sought to assess the timing and quantitative changes in AREs following GKRS in AVM patients. In all patients, the goal of therapy was complete AVM obliteration.

Inclusion of patients for the analysis required that patients have both clinical and radiological follow-up for a minimum of 2 years. Board-certified neurosurgeons logged the demographic data, prior endovascular intervention details, clinical presentation, and radiosurgery treatment details. Outcome measures were logged as well. AREs and the ARE index were computed from the MR images, which included T2-weighted or FLAIR sequences obtained through the region of the AVM on post-GKRS sequences. A maximum slice thickness of $5 \mathrm{~mm}$ or less was required on these MR sequences to perform reliable volumetric analysis of the changes.

\section{ARE Volumetric Assessment}

The volumes of the AVM nidus (estimated using the irradiated volume) and AREs were determined for each imaging data set available for patients in a longitudinal fashion. ARE volume was determined from T2-weighted or FLAIR MRI sequences, and the nidus volume was determined from postcontrast T1-weighted imaging used for the Gamma Knife treatment plan. Volumes were computed by segmenting the AREs and nidus on a slice-by-slice basis and numerically integrating them using the trapezoidal rule to compute the volume. ${ }^{27}$ The ImageJ software (National Institutes of Health) was used for contouring and volume computations. ARE regression was defined as a reduction of the T2 or FLAIR volume by more than $10 \%$ at its maximum volume after GKRS. ARE persistence or progression was defined as persistence or an increase in the ARE volume by more than $10 \%$ at last follow-up. The $10 \%$ variation for defining an unequivocal change was selected in part based on volumetric error estimation previously performed by our group over the range of lesion volumes commonly found in single-session GKRS. ${ }^{27}$

The ARE index was adapted from the edema index used to study edema response around benign and malignant tumors including meningiomas and metastases., ${ }^{7,20,22}$ At each time point for which an MR image was available, the mean ARE index for an AVM was computed as follows: mean ARE index $=($ volume on T2-weighted or
FLAIR changes)/(irradiated volume). For AVMs included in this study, the ARE index was computed until last follow-up MRI or until the time of resection or repeat radiosurgery if either approach was undertaken.

\section{Radiosurgery Treatment Protocol}

The details of GKRS procedures performed at our center have been reported previously. ${ }^{44}$ The Leksell Gamma Knife Unit Model U (Elekta AB) was used from May 1989 to July 2001, and the Model C was used from July 2001 to September 2009. The Gamma Knife Perfexion model was used after September 2009. Stereotactic biplane angiography was available for nidus definition and dose planning prior to 1991. Since 1991, stereotactic MRI was routinely used as a supplement to enhance the spatial accuracy of angiography for treatment planning. The Kula software was used for dose planning until June 1994 and then was replaced with GammaPlan software (both Elekta $A B$ ).

\section{AVM Follow-Up}

Earlier at our center, patients were subjected to a rigorous follow-up protocol with yearly angiography. With the introduction of MRI, patients underwent MRI at 6-month intervals for 2 years, and yearly afterward. When there was no nidus visible on MRI, the patient underwent angiography to confirm obliteration of the nidus. All of the images were analyzed both by a neurosurgeon and neuroradiologists. Patients were instructed to continue undergoing MRI every 3-5 years to monitor long-term complications even after their angiogram demonstrated that the AVM had been obliterated. For those patients for whom MRI was contraindicated (e.g., presence of a cardiac pacemaker), CT was performed instead of MRI.

\section{Statistical Analysis}

Descriptive statistics for all data are presented as the median and range for continuous variables and as frequency and percentages for categorical variables. Mean values are presented as the mean \pm SEM (standard error of the mean). Favorable outcome was defined as AVM obliteration and no posttreatment hemorrhage seizure or permanent symptomatic complications following treatment. Pretreatment patient and AVM characteristics were assessed in univariate analysis to test covariates predictive of outcome. The Spetzler-Martin grading scale and the Virginia Radiosurgery AVM Scale (VRAS) were assessed as previously described. Logistic regression modeling was used to analyze the prognostic factors of post-GKRS brain AREs and to assess odds ratios. Potential prognostic factors investigated included age, sex, nidus volume, nidus location, number of draining veins and their location (superficial or deep), prior hemorrhage or seizure, prior resection or endovascular embolization, T2-weighted imaging signals or encephalomalacia prior to GKRS, margin dose, and maximum dose. Factors with a $\mathrm{p}$ value $<0.15$ in univariate analysis were entered into multivariate analysis by forward selection. ${ }^{1}$ ARE indexes of different follow-up points were calculated and plotted to demonstrate the quantitative changes of brain AREs. The pre-stereotactic radiosurgery (SRS) nidus volume and the post-SRS maximal ARE index were further assessed by linear regression to model the 
relationship between initial nidus size and consequential AREs. All statistical tests were 2-sided, and $p<0.05$ was considered statistically significant. All statistical analyses were performed using IBM SPSS (version 20.0).

\section{Results \\ Cohort Overview}

Of the approximately 1400 patients with cerebral AVMs treated at our institution during the years 19872012, 105 patients had a complete clinical and radiological follow-up of more than 2 years. Clinical patient and AVM characteristics are listed in Table 1. In brief, the mean age at the time of GKRS was $32.6 \pm 15.63$ years. Males composed $50.5 \%(\mathrm{n}=53)$ of the population. The average nidus volume was $4.68 \pm 4.26 \mathrm{ml}$, with $38.1 \%(\mathrm{n}=40)$ of patients having a nidus volume $>4 \mathrm{ml}, 36.2 \%(\mathrm{n}=38)$ having a volume ranging from 2 to $4 \mathrm{ml}$, and $25.7 \%(\mathrm{n}=27)$ having a volume $<2 \mathrm{ml}$. Deep venous drainage was evident in $46.6 \%(n=49)$ of cases, and AVMs were in eloquent locations in $65.7 \%(n=69)$ of patients. $47.6 \%(n=50)$ of patients had a Spetzler-Martin AVM grades $\geq$ III; 22.8\% $(\mathrm{n}=24)$ had a VRAS of $0-1,35.2 \%(\mathrm{n}=37)$ had a VRAS of $2,29.5 \%(n=31)$ had a VRAS of 3 , and $12.4 \%(n=13)$ had a VRAS of 4 . A total of $48.6 \%(n=51)$ of patients had a hemorrhage prior to GKRS, and 3.8\% $(\mathrm{n}=4)$ had a hemorrhage after GKRS. Common presenting symptoms prior to GKRS included seizures $(31.4 \%, \mathrm{n}=33)$, headaches $(29.5 \%, \mathrm{n}=31)$, cranial nerve palsy/visual or hearing impairment $(19 \%, \mathrm{n}=20)$, long tract signs $(14.3 \%, \mathrm{n}=15)$, and speech impairment $(3.8 \%, \mathrm{n}=4) .21 .9 \%(\mathrm{n}=23)$ of patients had prior endovascular embolization, and $78.1 \%$ $(\mathrm{n}=82)$ had upfront GKRS. The median margin radiation dose was $22 \mathrm{~Gy}$, and the median maximum radiation dose was $40 \mathrm{~Gy}$. The average number of isocenters (shots) was 4 (median 2).

\section{Outcome Assessment}

Postradiosurgical Complications. The median clinical follow-up was 53.8 months (range 24-212 months). The median MRI follow-up was 36.8 months (range 24-212 months), and the median angiographic follow-up was 31.3 months (range 12-173 months). AREs were contoured for every patient, and the ARE index was calculated as previously explained. Figure 1 depicts the ARE index as a function of time after GKRS. The mean and median ARE volumes were calculated for each time period postGKRS. Table 2 details ARE data.

Post-GKRS hemorrhage occurred in 4 patients (3.8\%). Post-GKRS, $8.5 \%(\mathrm{n}=9)$ of patients were seizure free, $37.1 \%(\mathrm{n}=39)$ experienced less frequent seizures, and $11.4 \%(\mathrm{n}=12)$ had no change in seizure activity while $10.4 \%$ had a worsening or new seizure post-GKRS. Radiation-induced signs and symptoms included headache in $22.9 \%(\mathrm{n}=24)$ and focal neurological deficit in $20 \%(\mathrm{n}=$ 21). Focal neurological deficits included long tract signs $(9.5 \%, \mathrm{n}=10)$, mild cognitive impairment $(6.7 \%, \mathrm{n}=7)$, visual field deficits $(4.7 \%, \mathrm{n}=5)$, and speech impairment $(1.9 \%, \mathrm{n}=2)$.

Assessment of Obliteration. Overall, the MRI- and angiography-proven complete obliteration rate was $70.5 \%$ (n =74). Complete angiographic obliteration was achieved in
TABLE 1. Characteristics in 105 patients with an intracranial AVM treated with SRS

\begin{tabular}{|c|c|}
\hline Variable & Value $^{*}$ \\
\hline Median age in yrs & 32.6 (range 17-48.2) \\
\hline Sex (F/M) & $52(49.5) / 53(50.5)$ \\
\hline \multicolumn{2}{|l|}{ AVM features } \\
\hline \multicolumn{2}{|l|}{ Nidus vol in $\mathrm{ml}$} \\
\hline Mean & 4.68 (range 0.42-25.65) \\
\hline$<2$ & $27(25.7)$ \\
\hline $2-4$ & $38(36.2)$ \\
\hline$>4$ & $40(38.1)$ \\
\hline \multicolumn{2}{|l|}{ Deep vein drainage } \\
\hline Yes & $49(46.6)$ \\
\hline No & $56(53.4)$ \\
\hline \multicolumn{2}{|l|}{ Eloquent area } \\
\hline Yes & $69(65.7)$ \\
\hline No & $36(34.3)$ \\
\hline \multicolumn{2}{|l|}{ VRAS score } \\
\hline 0 & $6(5.7)$ \\
\hline 1 & $18(17.1)$ \\
\hline 2 & $37(35.2)$ \\
\hline 3 & $31(29.5)$ \\
\hline 4 & $13(12.4)$ \\
\hline \multicolumn{2}{|l|}{ Spetzler-Martin grade } \\
\hline I & $19(18.1)$ \\
\hline II & $36(34.2)$ \\
\hline III & $43(41)$ \\
\hline IV & $6(5.7)$ \\
\hline V & $1(0.9)$ \\
\hline \multicolumn{2}{|l|}{ AVM location } \\
\hline Frontal & $29(27.6)$ \\
\hline Temporal & $7(6.7)$ \\
\hline Parietal & $38(36.2)$ \\
\hline Occipital & $13(12.4)$ \\
\hline Thalamic \& basal ganglia & 17 (16.2) \\
\hline Brainstem & $1(0.9)$ \\
\hline Cerebellum & $2(1.9)$ \\
\hline \multicolumn{2}{|l|}{$\begin{array}{l}\text { Brain T2 signal before SRS (qualitative \& } \\
\text { vol) }\end{array}$} \\
\hline No. of patients & $46 / 69$ \\
\hline Signal vol on image in $\mathrm{ml}$ & $0-15.47$ \\
\hline \multicolumn{2}{|l|}{ Clinical presentation } \\
\hline \multicolumn{2}{|l|}{ Hemorrhage } \\
\hline Prior to SRS & $51(48.6)$ \\
\hline After SRS & $4(3.8)$ \\
\hline Seizure & $33(31.4)$ \\
\hline Headache & $31(29.5)$ \\
\hline CN palsy/visual or hearing disturbance & $20(19)$ \\
\hline Speech impairment & $4(3.8)$ \\
\hline Long tract sign & $15(14.3)$ \\
\hline Anterior motor syndrome & $2(1.9)$ \\
\hline
\end{tabular}


TABLE 1. Characteristics in 105 patients with an intracranial AVM treated with SRS (continued)

\begin{tabular}{lc}
\hline \multicolumn{1}{c}{ Variable } & Value $^{*}$ \\
\hline Clinical presentation (continued) & \\
\hline Hydrocephalus & $2(1.9)$ \\
\hline Cerebellar sign & $2(1.9)$ \\
\hline No. of prior embolizations & $23(21.9)$ \\
\hline No. of upfront GKRS procedures & $82(78.1)$ \\
\hline GKRS treatment parameters in Gy & \\
\hline Median margin radiation dose & 22 \\
\hline Median max radiation dose & 40 \\
\hline Median isodose level as \% & 50 \\
\hline Median follow-up in mos & 36.8 \\
\hline MRI & 31.3 \\
\hline Angiography & 53.8 \\
\hline Clinical
\end{tabular}

$\mathrm{CN}=$ cranial nerve.

* Values are reported as the number of patients (\%) unless stated otherwise.

$60.9 \%(n=64)$, and MRI obliteration was demonstrated in $13.3 \%(n=10)$ of patients. Subtotal obliteration (i.e., no evidence of nidus with an early draining vein heralding existing shunting) was noted in an additional 9.5\% $(\mathrm{n}=10)$, partial response $(50 \%-90 \%)$ was noted in $11.4 \%(n=12)$. Minimal nidal response to GKRS (i.e., nidal size changes of $10 \%-50 \%)$ was noted in $8.6 \%(n=9)$ of patients. Imaging outcome parameters are specified in Table 3.

Assessment of AREs and Obliteration. Among patients who showed complete AVM angiographic obliteration, $57.8 \%(n=37)$ developed appreciable AREs (defined as an ARE index $>8$ ). A similar incidence was seen in MRI-proven and otherwise-proven obliteration $(56.9 \%$ [n $=8]$ and $58.1 \%[n=43]$, respectively). Within this group, the median time for ARE appearance was 5 months (4-6 months) after GKRS; the median time for AREs to peak

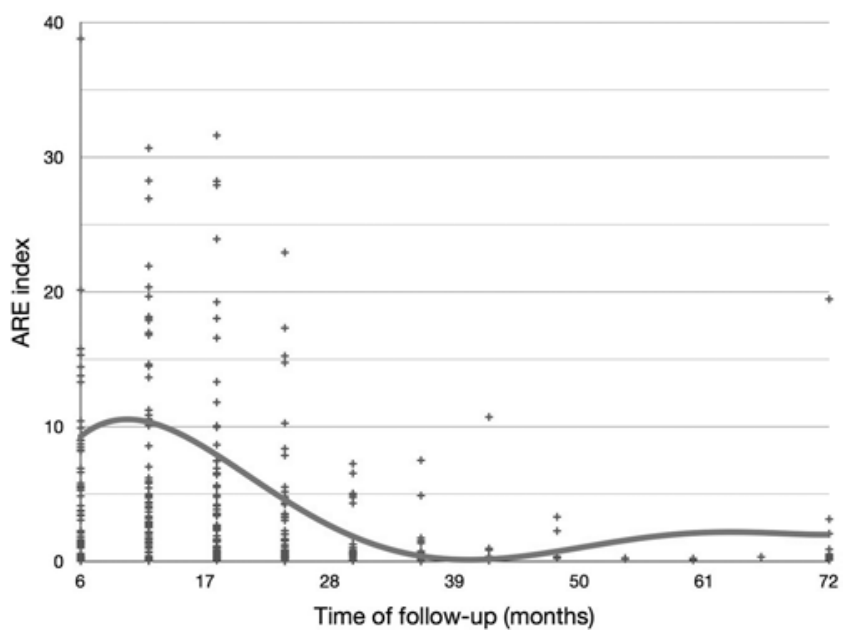

FIG. 1. ARE index for AVM following GKRS. The individual values available at each time point are denoted by a plus sign. The curve represents a best fit of the ARE indices with a peak at approximately 7-12 months following GKRS.
TABLE 2. ARE volume and ARE index

\begin{tabular}{ccccrc}
\hline & \multicolumn{2}{c}{ ARE Vol $(\mathrm{ml})$} & & \multicolumn{2}{c}{ ARE Index } \\
\cline { 2 - 3 } \cline { 5 - 6 } Time Point (mos) & Mean & Median & & Mean & Median \\
\hline $4-6$ & 15.6 & 8.57 & & 6.84 & 2.27 \\
\hline $7-12$ & 28.5 & 15.41 & & 12.92 & 4.79 \\
\hline $13-18$ & 19.3 & 7.19 & & 7.47 & 2.48 \\
\hline $19-24$ & 13.7 & 4.2 & & 3.34 & 1.38 \\
\hline $25-30$ & 7.77 & 3.32 & & 1.83 & 0.68 \\
\hline $31-36$ & 6.14 & 1.99 & & 1.28 & 0.53 \\
\hline $37-42$ & 3.04 & 1.49 & & 1.68 & 0.36 \\
\hline $43-48$ & 4.10 & 3.39 & & 1.29 & 0.82 \\
\hline $49-54$ & 0.48 & 0.42 & & 0.21 & 0.21 \\
\hline $55-60$ & 0.76 & 0.76 & & 0.15 & 0.15 \\
\hline $61-66$ & 1.87 & 1.87 & & 0.34 & 0.34 \\
\hline$>72$ & 6.82 & 1.57 & & 2.16 & 0.41 \\
\hline
\end{tabular}

as well as for a significant ARE index value to appear was 10 months (7-12 months) post-GKRS. These figures differed when considering the patients who exhibited subtotal obliteration of their AVM. In this patient group, AREs appeared with a greater delay after GKRS (median 10 months, range $7-12$ months post-GKRS), with peak values (as well as an appreciable ARE index value) seen with a median of 16 months (13-18 months) post-GKRS. This patient group also demonstrated an overall lower incidence of AREs at $50 \%(n=5)$. Patients eventually having either partial or minimal response to GKRS exhibited a significantly lower incidence of ARE formation $(33.3 \%$ $[n=4]$ and $44.4 \%[n=4]$, respectively). Of the cohort presented, 9 patients had an appreciable ARE index on the last clinical follow-up; complete nidus obliteration was not achieved in any of these patients.

Factors Associated With Significant ARE Development. We evaluated factors related to new or progressive AREs after GKRS (Table 4). In univariate analysis new or worsening AREs were associated with an initial nidus volume $\geq 3 \mathrm{ml}$ ( $\mathrm{p}=0.002$; OR 0.27 [95\% CI 0.12-0.61]), deep nidus location ( $\mathrm{p}=0.03$; OR 3.16 [95\% CI 1.128.87]), multiple draining veins ( $\mathrm{p}=0.012$; OR $0.65[95 \%$ CI 0.46-0.91]), multiple feeding arteries $(\mathrm{p}=0.038$; OR 0.62 [95\% CI 0.39-0.97]), evidence of prior hemorrhage $(\mathrm{p}=0.015$; OR 2.67 [95\% CI 1.21-5.88]), prior embolization ( $\mathrm{p}=0.008$; OR 0.25 [95\% CI 0.09-0.70]), and margin dose ( $\mathrm{p}=0.001$; OR 1.31 [95\% CI 1.13-1.52]).

In multivariate analysis, a new or worsening ARE was associated with an initial nidus volume $\geq 3 \mathrm{ml}(\mathrm{p}=0.043$; OR 0.36 [95\% CI 0.12-1.06]), deep nidus location ( $\mathrm{p}=$ 0.045; OR 4.15 [95\% CI 1.03-16.76]), multiple draining veins ( $\mathrm{p}=0.027$; OR 2.35 [95\% CI 0.69-8.01]), prior embolization ( $\mathrm{p}=0.05$; OR 0.88 [95\% CI 0.77-1.01]), and margin dose ( $\mathrm{p}=0.012$; OR 1.44 [95\% CI 1.08-1.92]). Prognostic factors associated with post-GKRS appreciable ARE index (>8) are listed in Table 4.

\section{Discussion}

This study highlights our experience at the University of Virginia Health System utilizing Gamma Knife radio- 
TABLE 3. Imaging outcome after SRS for AVM

\begin{tabular}{|c|c|c|c|c|c|}
\hline \multirow[b]{2}{*}{ Variable } & \multirow[b]{2}{*}{ No. of Patients (\%) } & \multicolumn{2}{|c|}{ Median Interval (mos) } & \multicolumn{2}{|c|}{ Appreciable ARE Index (>8) } \\
\hline & & Btwn GKRS \& ARE & $\begin{array}{c}\text { Btwn GKRS \& } \\
\text { Peak ARE }\end{array}$ & $\%$ Patients & $\begin{array}{c}\text { Median Time After } \\
\text { GKRS (mos) }\end{array}$ \\
\hline \multicolumn{6}{|l|}{ Obliteration } \\
\hline Angiography & $64(60.9)$ & 5 & 10 & 57.8 & 10 \\
\hline MRA & $10(13.3)$ & 5 & 10 & 56.9 & 10 \\
\hline Angiography \&/or MRI & $74(70.5)$ & 5 & 10 & 58.1 & 10 \\
\hline Subtotal obliteration* & $10(9.5)$ & 10 & 16 & 50 & 16 \\
\hline Partial response† & $12(11.4)$ & 5 & 10 & 33.3 & 7.5 \\
\hline Minimal responsef & $9(8.6)$ & 5 & 10 & 44.4 & 7.5 \\
\hline Overall & $105(100)$ & 5 & 10 & 52.4 & 10 \\
\hline
\end{tabular}

surgery for the treatment of cerebral AVMs. GKRS is an effective treatment option for appropriately selected AVM patients. Many studies have assessed patient and AVM characteristics to better predict outcome and estimate the risks of complications following radiosurgery. In the absence of treatment, the overall risk of a spontaneous bleed from a brain AVM appears to range from 1\% to 5\% per year, depending on various risk factors. ${ }^{24}$ Prior hemorrhage, a diffuse nidus, and high-risk features of nidus angioarchitecture raise the annual hemorrhage risk from approximately $1 \%$ in their absence to $8.94 \%$. We have previously reported an AVM radiosurgical grading system (the VRAS), factoring AVM volume, location, and prior hemorrhage for outcome prediction. ${ }^{38}$

The rate of obliteration proven either on angiography or MRI/MR angiography has been reported as $70 \%-86.5 \%$ in 5 years, depending on various factors. . $^{10,16,20,39,40}$ Fail- ure of obliteration is multifactorial and is related to dose, volume, inadequate recognition of the 3D geometry, recanalization of previously embolized components, or clotcompressed AVM that is subtotally treated. Studies from the University of Tokyo as well as reinterpretation of the outcome data from the Karolinska experience have suggested that there may be some protective benefit to AVMs even before complete obliteration of their nidus occurs. ${ }^{17,21}$

The literature offers little agreement on the issue of AREs. Different authors have referred to post-SRS lesions as radionecrosis, postradiation injury, adverse radiation effects, and delayed radionecrotic masses. Thus, the frequency with which said findings are reported varies from one study to the next. Foroughi et al. ${ }^{12}$ reported a $2.2 \%-9 \%$ incidence of necrotic masses after SRS, while Ganz et al. ${ }^{13}$ reported a $60 \%$ incidence for radiation-induced changes. Several factors, including radiation dose and target vol-

TABLE 4. Prognostic factors associated with post-SRS appreciable ARE index (> 8), using a logistic regression model

\begin{tabular}{|c|c|c|c|c|}
\hline \multirow[b]{2}{*}{ Variable } & \multicolumn{2}{|r|}{ Univariate } & \multicolumn{2}{|c|}{ Multivariate } \\
\hline & $p$ Value & OR $(95 \% \mathrm{Cl})$ & p Value & OR $(95 \% \mathrm{Cl})$ \\
\hline Age & 0.902 & $1(0.974-1.023)$ & & \\
\hline Sex (male vs female) & 0.920 & $1.04(0.484-2.236)$ & & \\
\hline Drainage vein (deep vs peripheral) & 0.379 & $0.71(0.328-1.527)$ & & \\
\hline Prior seizure (yes vs no) & 0.213 & $0.59(0.256-1.355)$ & & \\
\hline Prior surgical resection (yes vs no) & 0.713 & $0.8(0.234-2.705)$ & & \\
\hline T2 signal or encephalomalacia prior to SRS (yes vs no) & 0.614 & $0.77(0.278-2.131)$ & & \\
\hline Maximum dose & 0.468 & $1.02(0.961-1.090)$ & & \\
\hline Higher VRAS AVM score & 0.281 & $0.82(0.567-1.179)$ & & \\
\hline Higher Spetzler-Martin score & 0.273 & $1.28(0.822-1.998)$ & & \\
\hline Nidus vol (<3 vs $\geq 3 \mathrm{ml})$ & 0.002 & $0.27(0.122-0.612)$ & 0.043 & $0.36(0.12-1.06)$ \\
\hline Nidus location (lobar or deep) & 0.029 & $3.16(1.12-8.87)$ & 0.045 & $4.15(1.03-16.76)$ \\
\hline No. of drainage vein (multiple vs single) & 0.012 & $0.65(0.46-0.91)$ & 0.027 & $2.35(0.69-8.01)$ \\
\hline No. of feeding artery (multiple vs single) & 0.038 & $0.62(0.39-0.97)$ & 0.301 & $0.82(0.56-1.2)$ \\
\hline Prior hemorrhage (yes vs no) & 0.015 & $2.67(1.2-5.88)$ & 0.637 & $1.27(0.47-3.44)$ \\
\hline Prior embolization (yes vs no) & 0.008 & $0.25(0.09-0.70)$ & 0.050 & $0.88(0.77-1.01)$ \\
\hline Margin dose & 0.001 & $1.31(1.13-1.52)$ & 0.012 & $1.44(1.08-1.92)$ \\
\hline
\end{tabular}

* Values that appear in boldface are statistically significant at $\leq 0.05$. 
ume, are reported as important predictors for radiological changes. ${ }^{12-14}$ Other risk factors for ARE, such as prior hemorrhage, ${ }^{14}$ AVM location, ${ }^{9}$ and repeated radiosurgery, ${ }^{4}$ have been described in some series.

In this study, we have assessed overall pretreatment multivariate predictors of favorable outcome in a large patient cohort undergoing GKRS. Different demographic and clinical variables on presentation were logged, including presenting symptoms and signs, history of hemorrhage, AVM features, past surgical and endovascular treatments, T2-weighted imaging or encephalomalacia changes on MRI prior to treatment, as well as angioarchitectural features. Radiosurgical details were recorded as well (Table 1). Outcome parameters and follow-up features were logged next, including a detailed contouring of ARE volume and ARE index calculation as defined earlier on follow-up imaging, radiation-induced neurological deficits and symptoms, rates of obliteration, and hemorrhage during the latency period following treatment. Incidences are similar to those reported in the literature..$^{37}$ Through extensive follow-up, we have found that a significant number of patients with symptomatic radiation-induced changes will recover over time. ${ }^{43}$ An appreciable ARE index value defined after univariate and multivariate analysis (Table 4) was defined as a minimum ARE index $>8$.

As evident from Table 3 and Fig. 1, most patients develop AREs in the initial 7- to 12-month period after GKRS, with a noted delay in ARE development in those patients in whom subtotal obliteration is finally achieved (a median of 10 months to the ARE appearance and 16 months for the ARE peak). In accordance with previous reports stating that the development of AREs often predicts AVM obliteration for many patients, ${ }^{43}$ a similar finding is demonstrated in our cohort. The ARE index tool seems to better emphasize that patients who had only a subtotal, partial, or minimal angiographic response to GKRS also developed AREs to a much lower extent than patients who later developed a complete AVM nidus obliteration (Table 3). As illustrated in Fig. 2, it seems that the optimal scenario in terms of obliteration is the development of a significant ARE index 7-12 months after GKRS with its resolution coinciding with AVM nidus obliteration in the following 6 months.

In univariate analysis, nidus volume and location were found to be significant in the development of an appreciable ARE. Also significant were a few angioarchitectural features, such as the number of draining veins and the number of feeding arteries. Prior studies have also found history of hemorrhage to be a significant predictor of outcome following radiotherapy. ${ }^{19,32,37}$ Even if patients have enough time to allow for degradation of blood products, the definition of the field to apply radiation may not be as clearly defined. Similarly, our data show that prior hemorrhage significantly affects the development of a significant ARE index post-GKRS. AVM location in terms of lobes as well as pre-GKRS T2-weighted imaging or encephalomalacia changes were not found to significantly affect appreciable ARE index development. Prior embolization, as reported previously, was found to significantly influence appreciable ARE index development $>8$, which was also associated with maximum dose delivered to the nidus (Table 4). Somewhat surprisingly, a higher Spetzler-Mar- tin AVM grade, as well as a higher VRAS score, did not influence the incidence of appreciable ARE development (Table 3).

Post-GKRS, $45.6 \%(n=48)$ of patients were either seizure free or experienced less frequent seizures (Engel Class I or II), and $11.4 \%(n=12)$ had no change in seizure activity while $10.4 \%$ had a worsening or new seizure postGKRS. Radiation-induced signs and symptoms included headache in $22.9 \%(\mathrm{n}=24)$ and focal neurological deficit in $20 \%(\mathrm{n}=21)$. Focal neurological deficits included long tract signs $(9.5 \%, \mathrm{n}=10)$, mild cognitive impairment $(6.7 \%, \mathrm{n}=7)$, visual field deficits $(4.7 \%, \mathrm{n}=5)$, and speech impairment $(1.9 \%, \mathrm{n}=2)$ in incidences similar to those reported elsewhere.

\section{AREs as a Predictor of Future Obliteration}

Plotting time to complete obliteration versus the presence of an appreciable ARE index, as seen in Fig. 3, demonstrates an important conclusion. A statistically significant influence of the presence of an ARE index $>8$ on the time of obliteration is seen; that is, the presence of an appreciable ARE index during the initial follow-up (peaks at 7-12 months post-GKRS) is a strong predictor of complete obliteration, with a mean time of $62.79 \pm 9.78$ months versus $80.87 \pm 9.3$ months and a median of 30.46 months (SD 3.84 months) versus 53.46 months (SD 9.61 months) $(\mathrm{p}=0.043)$. When plotting time to subtotal obliteration, partial or minimal obliteration versus appreciable ARE development, no such correlation is seen. Thus, there is no direct influence of ARE development on the final outcome in cases of subtotal, partial, or minimal response, with a mean of $144.0 \pm 17.94$ months versus $143.93 \pm 12.45$ months for subtotal obliteration $(\mathrm{p}=0.706), 158.64 \pm 17.6$ months versus $135.28 \pm 12.57$ months $(\mathrm{p}=0.605)$ for partial obliteration, and $159.24 \pm 15.02$ months versus 155.2 \pm 9.93 months $(\mathrm{p}=0.602)$ for minimal obliteration. There are several different explanations as to the physiology and meaning of early versus late ARE development. Early appreciable AREs (ARE index > 8) are likely a reflection of venous stasis or even thrombosis of the draining vein that leads to obliteration. Late appreciable AREs (ARE index $>8$ ) are likely due to deleterious radiation effects upon the brain parenchyma itself with resultant inflammatory process rather than purely vascular changes. Some degree of inflammation is likely a part of both processes but less so in the early ARE development. ${ }^{43}$

\section{The Lack of Concordance to Spetzler-Martin Grade}

Studies have shown that radiosurgery is a safe and less invasive alternative treatment in AVM patients who are either medically unsuitable or unwilling to undergo surgical removal. ${ }^{22,26,28}$ Further analysis demonstrates that patient and AVM characteristics differ between series of microsurgery and radiosurgery.

In the present study, $41 \%$ of patients had a SpetzlerMartin Grade III AVM and an additional 6.6\% had a Spetzler-Martin Grade IV or V AVM, representing a poor surgical outcome. This grading system has undergone several modifications to allow for the different subtypes and different outcome parameters in those treated with radiosurgery versus microsurgery. De Oliveira et al. amended 

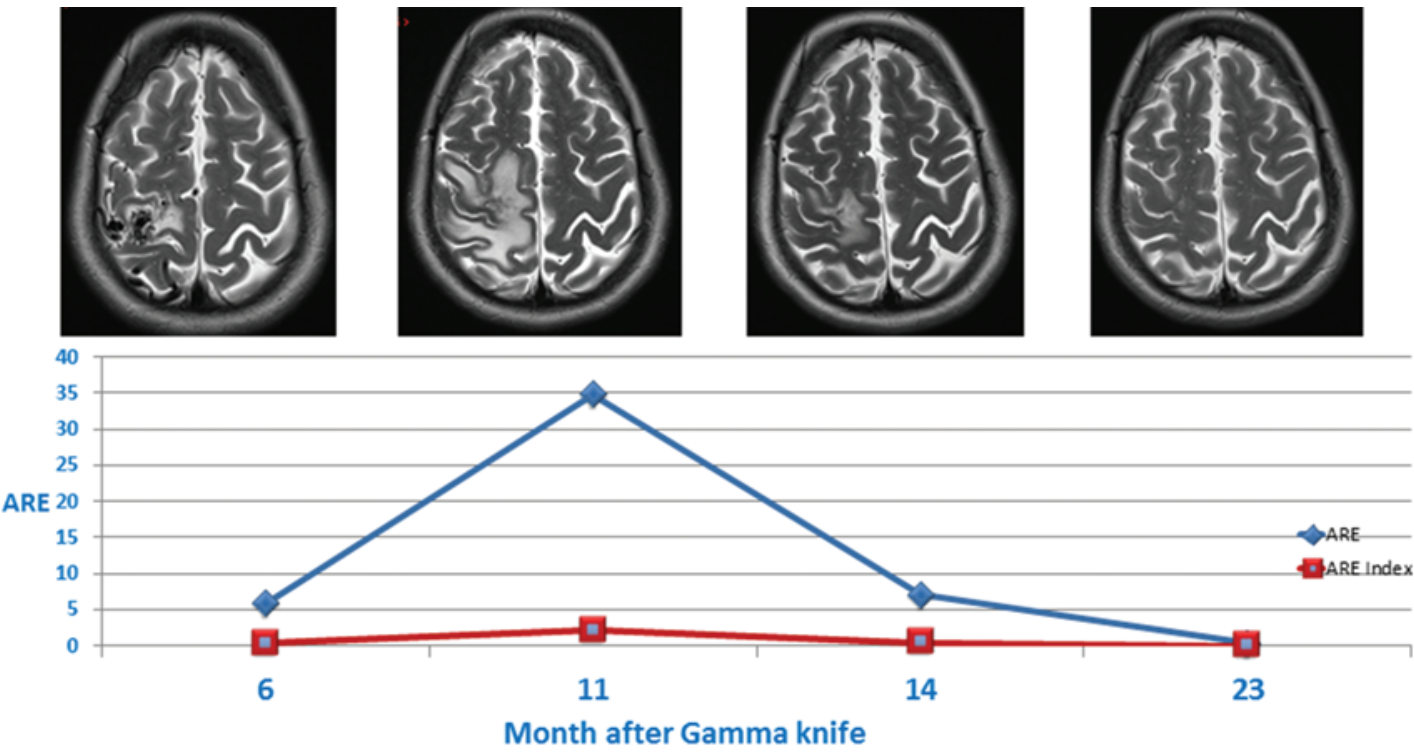

FIG. 2. A 38-year-old sample patient treated with GKRS for a right posterior frontal, Spetzler-Martin Grade III AVM. The patient suffered hemorrhage that manifested with seizures and focal headaches. No prior embolization was done. Irradiated nidal volume measured $16.15 \mathrm{~cm}$. The patient recieved a peripheral dose of $16 \mathrm{~Gy}$ to the $50 \%$ isodose line using 20 isocenters (shots). Followup months are plotted against ARE volume (blue line) and ARE index (red line). Representative T2-weighted images showing the complete obliteration are shown on the top. Figure is available in color online only.

the Spetzler-Martin grading scale to include lesions that are Grade III due to large size (Grade IIIA) or eloquent and deep locations (Grade IIIB). ${ }^{7}$

It seems evident that patients undergoing radiosurgery for AVM experience different prognostic horizons from those treated with microsurgery and that they require dedicated unique assessment tools for early subgroup population recognition and intervention. The measurement of AREs and ARE index seem to add new data to patient follow-up and choice of treatment to known assessment tools. The decision to continue with conservative follow-up or re-treat the nidus with repeat radiosurgery, embolization, or surgery is a dilemma faced daily by neurosurgeons. The ARE index adds important prognostic data at this crucial decision-making point, in terms of short- and long-term outcome parameters, including both obliteration and clinical manifestations.

\section{Study Limitations}

The current study comprises a fraction of the total number of AVM patients treated with SRS at our institution. The limitations of this study include a combination of factors related to prospective and retrospective data collection. The external validity may be limited by patient selection bias inherent to our treatment algorithms. Patients who developed postradiosurgery complications were followed more closely and had more frequent imaging and clinical workups, and thus might be over-represented in this cohort. On the other hand, patients with ARE who were asymptomatic may have been underestimated by the study secondary to a lack of T2-weighted MR images in all post-SRS AVM patients.

Additionally, although evaluation of a large number of patients with long-term follow-up is a major strength of this analysis, treatment was carried out over a long time period and was subject to change. Since 1991, stereotactic MRI was routinely used as a supplement to enhance the spatial accuracy of angiography for treatment planning. Radiosurgical technology and treatment algorithms have been refined over the study period, and this could have contributed to a bias. However, despite these improvements, there was no significant difference in obliteration rates over time.

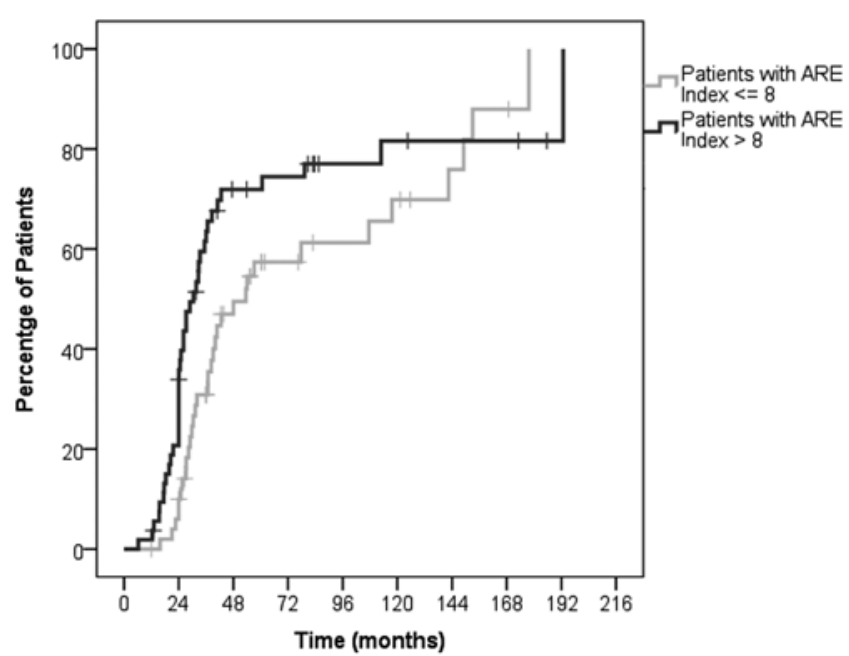

FIG. 3. Time to complete obliteration (actual data). Patients are stratified into those who developed a significant ARE index (defined as $>8$ ) and those who did not. As shown, patients with a high ARE index (i.e., > 8) reached complete obliteration significantly sooner. Mean time of $62.79 \pm$ 9.78 months versus $80.87 \pm 9.3$ months and a median of 30.46 months (SD 3.84 months) versus 53.46 months (SD 9.61 months) $(p=0.043$ ). 


\section{Conclusions}

AREs follow a specific temporal pattern after radiosurgery with a peak at a median of 10 months (range 7-12 months). Those with later-onset (>12 months) AREs after SRS are less likely to achieve complete obliteration. A minimum ARE index $>8$ is significantly influenced by $\mathrm{AVM}$ volume, location, and angioarchitecture features as well as prior hemorrhage history and treatment parameters. The ARE index also relates to the probability of nidal obliteration.

\section{Acknowledgments}

Multiple clinicians have contributed to this radiosurgery experience. We would like to thank Ladislau Steiner, Neal Kassell, Dheerendra Prasad, Jacques Dion, Kenny Liu, Avery Evans, and Mary Jensen for their efforts in the treatment and follow-up of these patients. We thank Dr. Ahmed Awad for his contribution to this manuscript.

\section{References}

1. Atkinson RP, Awad IA, Batjer HH, Dowd CF, Furlan A, Giannotta SL, et al: Reporting terminology for brain arteriovenous malformation clinical and radiographic features for use in clinical trials. Stroke 32:1430-1442, 2001

2. Al-Shahi R, Bhattacharya JJ, Currie DG, Papanastassiou V, Ritchie V, Roberts RC, et al: Scottish Intracranial Vascular Malformation Study (SIVMS): evaluation of methods, ICD10 coding, and potential sources of bias in a prospective, population-based cohort. Stroke 34:1156-1162, 2003

3. Bollet MA, Anxionnat R, Buchheit I, Bey P, Cordebar A, Jay $\mathrm{N}$, et al: Efficacy and morbidity of arc-therapy radiosurgery for cerebral arteriovenous malformations: a comparison with the natural history. Int J Radiat Oncol Biol Phys 58:13531363,2004

4. Buis DR, Meijer OW, van den Berg R, Lagerwaard FJ, Bot JC, Slotman BJ, et al: Clinical outcome after repeated radiosurgery for brain arteriovenous malformations. Radiother Oncol 95:250-256, 2010

5. Chang JH, Chang JW, Park YG, Chung SS: Factors related to complete occlusion of arteriovenous malformations after gamma knife radiosurgery. J Neurosurg 93 (Suppl 3):96101,2000

6. Cockroft KM: Unruptured brain arteriovenous malformations should be treated conservatively: no. Stroke 38:33103311,2007

7. de Oliveira E, Tedeschi H, Raso J: Comprehensive management of arteriovenous malformations. Neurol Res 20:673683, 1998

8. Fiehler J, Stapf C: ARUBA-beating natural history in unruptured brain AVMs by intervention. Neuroradiology 50:465-467, 2008

9. Flickinger JC, Kondziolka D, Maitz AH, Lunsford LD: Analysis of neurological sequelae from radiosurgery of arteriovenous malformations: how location affects outcome. Int J Radiat Oncol Biol Phys 40:273-278, 1998

10. Flickinger JC, Kondziolka D, Maitz AH, Lunsford LD: An analysis of the dose-response for arteriovenous malformation radiosurgery and other factors affecting obliteration. Radiother Oncol 63:347-354, 2002

11. Flickinger JC, Pollock BE, Kondziolka D, Lunsford LD: A dose-response analysis of arteriovenous malformation obliteration after radiosurgery. Int J Radiat Oncol Biol Phys 36:873-879, 1996

12. Foroughi M, Kemeny AA, Lehecka M, Wons J, Kajdi L, Hatfield R, et al: Operative intervention for delayed symptomatic radionecrotic masses developing following stereotactic radiosurgery for cerebral arteriovenous malformations-case analysis and literature review. Acta Neurochir (Wien) 151:9-19, 2009

13. Ganz JC, Reda WA, Abdelkarim K: Adverse radiation effects after gamma knife surgery in relation to dose and volume. Acta Neurochir (Wien) 152:803-815, 2010

14. Hayhurst C, Monsalves E, van Prooijen M, Cusimano M, Tsao M, Menard C, et al: Pretreatment predictors of adverse radiation effects after radiosurgery for arteriovenous malformation. Int J Radiat Oncol Biol Phys 82:803-808, 2012

15. Inoue $\mathrm{HK}$, Ohye $\mathrm{C}$ : Hemorrhage risks and obliteration rates of arteriovenous malformations after gamma knife radiosurgery. J Neurosurg 97 (5 Suppl):474-476, 2002

16. Kano H, Kondziolka D, Flickinger JC, Yang HC, Flannery TJ, Awan NR, et al: Stereotactic radiosurgery for arteriovenous malformations, Part 3: outcome predictors and risks after repeat radiosurgery. J Neurosurg 116:21-32, 2012

17. Karlsson B, Lax I, Söderman M: Risk for hemorrhage during the 2-year latency period following gamma knife radiosurgery for arteriovenous malformations. Int J Radiat Oncol Biol Phys 49:1045-1051, 2001

18. Lawton MT, Kim H, McCulloch CE, Mikhak B, Young WL: A supplementary grading scale for selecting patients with brain arteriovenous malformations for surgery. Neurosurgery 66:702-713, 2010

19. Liscák R, Vladyka V, Simonová G, Urgosík D, Novotný J $\mathrm{Jr}$, Janousková L, et al: Arteriovenous malformations after Leksell gamma knife radiosurgery: rate of obliteration and complications. Neurosurgery 60:1005-1016, 2007

20. Lunsford LD, Kondziolka D, Flickinger JC, Bissonette DJ, Jungreis CA, Maitz AH, et al: Stereotactic radiosurgery for arteriovenous malformations of the brain. J Neurosurg 75:512-524, 1991

21. Maruyama K, Shin M, Tago M, Kishimoto J, Morita A, Kawahara N: Radiosurgery to reduce the risk of first hemorrhage from brain arteriovenous malformations. Neurosurgery 60:453-, 2007

22. Nataf F, Schlienger M, Bayram M, Ghossoub M, George B, Roux FX: Microsurgery or radiosurgery for cerebral arteriovenous malformations? A study of two paired series. Neurosurgery 61:39-50, 2007

23. Ogilvy CS, Stieg PE, Awad I, Brown RD Jr, Kondziolka D, Rosenwasser R, et al: AHA Scientific Statement: Recommendations for the management of intracranial arteriovenous malformations: a statement for healthcare professionals from a special writing group of the Stroke Council, American Stroke Association. Stroke 32:1458-1471, 2001

24. Ondra SL, Troupp H, George ED, Schwab K: The natural history of symptomatic arteriovenous malformations of the brain: a 24-year follow-up assessment. J Neurosurg 73:387391, 1990

25. Perret G, Nishioka H: Report on the cooperative study of intracranial aneurysms and subarachnoid hemorrhage. Section VI. Arteriovenous malformations. An analysis of 545 cases of cranio-cerebral arteriovenous malformations and fistulae reported to the cooperative study. J Neurosurg 25:467-490, 1966

26. Pollock BE, Flickinger JC: A proposed radiosurgery-based grading system for arteriovenous malformations. J Neurosurg 96:79-85, 2002

27. Pollock BE, Flickinger JC: Modification of the radiosurgerybased arteriovenous malformation grading system. Neurosurgery 63:239-243, 2008

28. Pollock BE, Gorman DA, Coffey RJ: Patient outcomes after arteriovenous malformation radiosurgical management: results based on a 5- to 14-year follow-up study. Neurosurgery 52:1291-1297, 2003

29. Pollock BE, Gorman DA, Schomberg PJ, Kline RW: The 
Mayo Clinic gamma knife experience: indications and initial results. Mayo Clin Proc 74:5-13, 1999

30. Sasaki T, Kurita H, Saito I, Kawamoto S, Nemoto S, Terahara A, et al: Arteriovenous malformations in the basal ganglia and thalamus: management and results in 101 cases. J Neurosurg 88:285-292, 1998

31. Shin M, Kawamoto S, Kurita H, Tago M, Sasaki T, Morita A, et al: Retrospective analysis of a 10-year experience of stereotactic radio surgery for arteriovenous malformations in children and adolescents. J Neurosurg 97:779-784, 2002

32. Shin M, Maruyama K, Kurita H, Kawamoto S, Tago M, Terahara A, et al: Analysis of nidus obliteration rates after gamma knife surgery for arteriovenous malformations based on long-term follow-up data: the University of Tokyo experience. J Neurosurg 101:18-24, 2004

33. Spetzler RF, Martin NA: A proposed grading system for arteriovenous malformations. J Neurosurg 65:476-483, 1986

34. Stapf C, Mast H, Sciacca RR, Berenstein A, Nelson PK, Gobin YP, et al: The New York Islands AVM Study: design, study progress, and initial results. Stroke 34:e29-e33, 2003

35. Stapf C, Mohr JP: Unruptured brain arteriovenous malformations should be treated conservatively: yes. Stroke 38:33083309, 2007

36. Stapf C, Mohr JP, Choi JH, Hartmann A, Mast H: Invasive treatment of unruptured brain arteriovenous malformations is experimental therapy. Curr Opin Neurol 19:63-68, 2006

37. Starke RM, Komotar RJ, Hwang BY, Fischer LE, Otten ML, Merkow MB, et al: A comprehensive review of radiosurgery for cerebral arteriovenous malformations: outcomes, predictive factors, and grading scales. Stereotact Funct Neurosurg 86:191-199, 2008

38. Starke RM, Yen CP, Ding D, Sheehan JP: A practical grading scale for predicting outcome after radiosurgery for arteriovenous malformations: analysis of 1012 treated patients. J Neurosurg 119:981-987, 2013

39. Steiner L, Leksell L, Forster DM, Greitz T, Backlund EO: Stereotactic radiosurgery in intracranial arterio-venous malformations. Acta Neurochir (Wien) Suppl 21:195-209, 1974

40. Steiner L, Leksell L, Greitz T, Forster DM, Backlund EO: Stereotaxic radiosurgery for cerebral arteriovenous malfor- mations. Report of a case. Acta Chir Scand 138:459-464, 1972

41. Wegner RE, Oysul K, Pollock BE, Sirin S, Kondziolka D, Niranjan A, et al: A modified radiosurgery-based arteriovenous malformation grading scale and its correlation with outcomes. Int J Radiat Oncol Biol Phys 79:1147-1150, 2011

42. Yamamoto M, Jimbo M, Hara M, Saito I, Mori K: Gamma knife radiosurgery for arteriovenous malformations: longterm follow-up results focusing on complications occurring more than 5 years after irradiation. Neurosurgery 38:906914, 1996

43. Yen CP, Matsumoto JA, Wintermark M, Schwyzer L, Evans AJ, Jensen ME, et al: Radiation-induced imaging changes following Gamma Knife surgery for cerebral arteriovenous malformations. J Neurosurg 118:63-73, 2013

44. Yen CP, Sheehan JP, Schwyzer L, Schlesinger D: Hemorrhage risk of cerebral arteriovenous malformations before and during the latency period after Gamma Knife radiosurgery. Stroke 42:1691-1696, 2011

45. Yen CP, Varady P, Sheehan J, Steiner M, Steiner L: Subtotal obliteration of cerebral arteriovenous malformations after Gamma Knife surgery. J Neurosurg 106:361-369, 2007

\section{Author Contributions}

Conception and design: Sheehan, Cohen-Inbar. Acquisition of data: Cohen-Inbar, Sheehan. Analysis and interpretation of data: Cohen-Inbar, Lee, Schlesinger, Sheehan. Drafting the article: Cohen-Inbar, Sheehan. Critically revising the article: all authors. Reviewed submitted version of manuscript: all authors. Approved the final version of the manuscript on behalf of all authors: Sheehan. Statistical analysis: Cohen-Inbar, Lee, Schlesinger. Study supervision: Sheehan.

\section{Correspondence}

Jason Sheehan, Department of Neurological Surgery, University of Virginia Health System, Charlottesville, VA 22908. email: jsheehan@virginia.edu. 